\title{
Diabetes and COVID-19: evidence, current status and unanswered research questions
}

\author{
Ritesh Gupta ${ }^{1}$ - Akhtar Hussain ${ }^{2,3} \cdot$ Anoop Misra $\mathbb{D}^{1,4,5}$
}

Received: 19 April 2020 / Revised: 23 April 2020 / Accepted: 28 April 2020 / Published online: 13 May 2020

(c) Springer Nature Limited 2020

\begin{abstract}
Patients with diabetes who get coronavirus disease 2019 (COVID-19) are at risk of a severe disease course and mortality. Several factors especially the impaired immune response, heightened inflammatory response and hypercoagulable state contribute to the increased disease severity. However, there are many contentious issues about which the evidence is rather limited. There are some theoretical concerns about the effects of different anti-hyperglycaemic drugs. Similarly, despite the recognition of angiotensin converting enzyme 2 (ACE2) as the receptor for severe acute respiratory syndrome coronavirus 2 (SARS CoV-2), and the role of ACE2 in lung injury; there are conflicting results with the use of angiotensin converting enzyme (ACE) inhibitors and angiotensin receptor blockers (ARB) in these patients. Management of patients with diabetes in times of restrictions on mobility poses some challenges and novel approaches like telemedicine can be useful. There is a need to further study the natural course of COVID-19 in patients with diabetes and to understand the individual, regional and ethnic variations in disease prevalence and course.
\end{abstract}

\section{Background}

The high prevalence of diabetes globally makes it a frequent comorbidity in patients with coronavirus-associated disease 2019 (COVID-19). Though diabetes increases the risk of infection in general, most studies have reported prevalence of diabetes almost similar to that in general population in patients with COVID-19. A meta-analysis of eight trials in China showed that diabetes was present in $8 \%$ of 46,248 patients with COVID-19 [1]. Understandably, prevalence of diabetes in patients with COVID-19 varies by region, age and ethnicity. It is not known whether patients with diabetes with well-controlled blood glucose levels have an increased

$\triangle$ Anoop Misra

anoopmisra@gmail.com

1 Fortis CDOC Hospital, Chirag Enclave, New Delhi, India

2 Chronic Disease-Diabetes, NORD University, Stjørdal, Norway

3 Medicine, Federal University of Ceara (UFC), Ceara, Brazil

4 National Diabetes, Obesity and Cholesterol Foundation, New Delhi, India

5 Diabetes Foundation (India), New Delhi, India risk of infection with severe acute respiratory syndrome coronavirus 2 (SARS CoV-2).

\section{Why patients with diabetes have increased severity and mortality?}

Patients with diabetes who develop COVID-19 have been seen to have a worse prognosis and increased mortality in most studies. In 201 Chinese patients with diabetes a hazard ratio of $2.34(95 \% \mathrm{CI}, 1.35-4.05 ; p=0.002)$ for acute respiratory distress syndrome (ARDS) [2] has been reported. Further, meta-analysis of nine studies from China $(n=$ 1936) showed a significant correlation between severity of COVID-19 and diabetes (OR, 2.67, 95\% CI; 1.91-3.74; $p<$ 0.01 ) [3]. Similarly, case fatality rate was $7.3 \%$ in patients with diabetes as opposed to $2.3 \%$ in those without diabetes in a report of 44,672 patients of COVID-19 by Chinese Centre for Disease Control [4]. A recent study in 1122 patients with COVID-19 in 88 centres across the USA found diabetes to be associated with more than fourfold increase in mortality [5].

How diabetes increases severity of COVID-19 is unclear, though several factors may be responsible (Table 1). Poor glycaemic control impairs several aspects of the innate and adaptive immune response to viral infections and to the 
Table 1 Reasons of increased severity of COVID-19 in diabetes based on various studies (mostly unadjusted analyses).

Established

(1) Glycaemic instability: hyperglycaemia and possibly hypoglycaemia

(2) Immune defects especially impaired T-cell response

(3) Associated comorbidities like obesity, heart and kidney diseases

Postulated

(1) Chronic subclinical inflammation, increased interleukin 6

(2) Increased plasmin

(3) Reduced ACE2

(4) Increased furin (involved in entry of virus into cell)

potential secondary bacterial infection in the lungs $[6,7]$. Defects in immunity namely inappropriate T-cell action, impaired natural killer cell activity and defects in complement action could reduce viral clearance [8]. Interestingly, ARDS in patients with COVID-19 is driven by severe hypoxaemia despite relatively well-preserved lung mechanics. Pre-existing proinflammatory state could accentuate the cytokine storm, which is believed to be responsible for ARDS as well as multi-organ dysfunction in COVID-19 [9]. In this context, it is important to note that there is strong association between type 2 diabetes, obesity and abnormal secretion of adipokines and cytokines like TNF-alfa and interferon, which may further impair immunity and predispose to severe infection [10]. Further, diabetes is associated with increased plasminogen levels which has been postulated to increase the virulence of SARS CoV-2 [11]. Presence of these inflammation and prothrombotic factors has been shown in a study in 174 patients hospitalised with COVID-19 in Wuhan, China; significantly higher serum levels of interleukein 6, erythrocyte sedimentation rate, Creactive protein, ferritin, fibrinogen and D-dimer were reported in patients with diabetes compared with those without diabetes [12]. Increased viral replication in diabetes may also due to an increase in furin, which is a type-1 membranebound protease involved in the entry of coronaviruses into the cell [13]. In addition, pre-existing comorbidities associated with diabetes like hypertension, coronary artery disease and chronic kidney disease further worsen the prognosis. Lastly, hypoglycaemia which could occur during treatment of diabetes may additionally worsen the clinical outcomes.

In this respect role of angiotensin converting enzyme 2 (ACE2) receptor in pathogenesis of COVID-19 in patients with diabetes is intriguing. SARS CoV-2 enters the cell by binding to ACE2, a process which involves many steps and several enzymes and proteins [14]. There is experimental evidence for downregulation of ACE2 in diabetes [15], which may predispose to more severe lung injury. On the other hand, ACE2 is a receptor for SARS CoV-2 and this downregulation might reduce the entry of virus into cells. These issues are further discussed below in context of use of anti-hyperglycemic and anti-hypertensive drugs.

\section{Anti-hyperglycaemic drugs: correct selection and potential problems}

The precise effect of treatment with various oral antihyperglycaemic agents on the severity of COVID-19 is not known, though there are some theoretical considerations. Metformin has shown modest benefits in lower respiratory tract infections and pulmonary tuberculosis [16], though gastrointestinal tolerability in sick patients is of concern. Thiazolidinediones have been shown to increase ACE2 levels [17]. However, propensity of thiazolidinediones to cause fluid retention and the risk of congestive heart failure in COVID-19 would make these agents unfavourable for treatment. Glucagon-like peptide-1 agonists have has been shown to increase ACE2 and increase surfactant in experimental animals [18]. Practical significance of changes in ACE2 levels with use of thiazolidinediones and glucagon-like peptide-1 agonists is not known. Sulfonylureas are effective, but the risk of hypoglycaemia especially in the setting of irregular meals might preclude their use. Nevertheless, sulfonylureas can be considered whenever blood glucose monitoring is possible.

There is some data regarding use of dipeptidyl peptidase 4 (DPP4) inhibitors from previous viral epidemics. DPP4 is the prime receptor for Middle East respiratory syndrome coronavirus responsible for its entry into cell [19]. Hence the possibility of DPP4 facilitating the entry of SARS CoV-2 into the cell cannot be ruled out. In that context, it is an interesting postulation that widespread use of DPP4 inhibitors in India and many other countries might be protecting individuals with diabetes from this infection. On the other hand, DPP4 inhibitors can potentially interfere with immune response which may be harmful, but clinical data from DPP4 inhibitors has shown that this is generally not the case [20].

There is increasing use of sodium glucose cotransporter 2 (SGLT-2) inhibitors worldwide and in India. Interestingly, SGLT-2 inhibitors could also activate ACE2 indirectly especially if used along with ACE inhibitors [21]. There is a hypothetical possibility of SGLT-2 inhibitors reducing lactate production because of reduction in oxygen demand of tissues, which could reduce viral entry by raising cytosolic pH [22]. Further, caution about dehydration and the possibility of euglycaemic ketoacidosis need to be observed when using SGLT-2 inhibitors in sick patients with COVID-19. Insulin has also been shown to increase ACE2 expression by attenuating the effect of a disintegrin and metalloprotease (ADAM-17) [23]. Practical relevance of these findings is not known at present. In any case, insulin 
remains the agent of choice to control sugars in hospitalised patients with COVID-19. This however necessitates frequent monitoring of blood glucose and poses some practical concerns in terms of increasing the exposure of healthcare provider to the COVID-19 patient. Strategies like single dose of basal insulin and self-monitoring of glucose by patients are worth considering in that context. Further, technologies like remote continuous glucose monitoring and insulin pump could be useful.

Thus, it appears safe to continue the usual antihyperglycemic medications in most patients who have mild infection, good general condition and normal oral intake. However, SGLT-2 inhibitors might need discontinuation due to the risk of dehydration and euglycaemic ketoacidosis. Metformin may also need to be stopped if there is vomiting or poor oral intake. Doses of other antihyperglyacemic drugs like sulfonylureas and insulin may have to be altered depending upon the blood glucose levels. Hospitalised patients especially those requiring intensive care would need insulin for glycaemic control.

\section{Drugs for treatment of comorbidities in diabetes}

\section{Angiotensin converting enzyme (ACE) inhibitors/ angiotensin receptor blockers (ARB)}

These are commonly used drugs in patients with diabetes, especially in those with hypertension and kidney dysfunction. There have been a lot of literature and debate whether these drugs could benefit or harm patients having COVID19 infection. This issue is discussed below.

\section{Scientific experimental data that support potential harm duet to ACE inhibitors/ARB in COVID-19}

There has been a lot of interest in ACE inhibitors and ARBs following the identification of ACE2 as the receptor for SARS CoV-2. ACE inhibitors and ARBs increase the levels of ACE2 by inhibiting the conversion of angiotensin 1 to angiotensin 2. Increased ACE2 expression could theoretically increase viral binding and entry into cell, though there is no clinical evidence to support this otherwise attractive hypothesis. Reduced angiotensin 2 as a result of ACE inhibition and increased angiotensin 1-7 as a result of increased activity of ACE2 could reduce the cytosolic $\mathrm{pH}$, which could result in more favourable environment for viral endocytosis [24]. Also, angiotensin 1-7 has been shown to increase sympathetic activity by acting on Mas receptors in the brainstem, which could contribute to cardiovascular morbidity observed in these patients [25]. However, most of these concerns are hypothetical with minimal evidence.
Scientific experimental data that support benefit due to ACE inhibitors/ARB in COVID-19

Increased ACE2 might not result in increased viral entry because of the limited availability of the serine protease TMPRSS2, which is required for viral binding [20]. Increased ACE2 and consequently angiotensin 1-7 have vasodilatory and antifibrotic effects and have been shown to be protective against lung injury in animals [26]. Treatment with ARBs was reported to reduce mortality in Ebola virus infection [27]. Previously, a small study in ten patients with ARDS showed that recombinant ACE2 was well tolerated and led to an increase in angiotensin (1-7) levels [28].

\section{Clinical studies with ACE inhibitors/ARBs in COVID-19}

(1) There are no controlled studies on the use of ACE inhibitors and ARBs in patients with COVID-19.

(2) The clinical evidence is inconclusive. While one study in China did not find any association of ACE inhibitor use with severity of disease, there was an increased mortality in patients with COVID-19 receiving ACE inhibitors and ARBs in another study [29, 30]. One study in the USA did not find any significant difference in mortality in patients who received ACE inhibitors and ARBs and those who did not [31]. A recently published study in 1128 patients hospitalised with COVID-19 in nine hospitals in Hubei, China showed significantly reduced all-cause mortality with the use of ACE inhibitors or ARBs compared with other anti-hypertensive drugs [32].

(3) Many patients with COVID-19 have shown hypokalemia indicating activation of RAS [33], and ACE inhibitors and ARBs may have a role [34].

In this subject situation is far from clear and there are too many unknown factors, which might be operative in the interaction between ACE2, diabetes, ACE inhibitors/ARBs and lung injury. The lack of evidence for either benefit or harm has prompted European Society of Cardiology Council on Hypertension, European Society of Hypertension and American Heart Association to advise continuing with ACE inhibitors and ARBs in case a patient develops COVID-19 [35]. A clinical trial is underway to study the ARB losartan and recombinant human ACE2 in patients with COVID-19.

\section{Unanswered questions}

There have been several commentaries on the relationship between diabetes and COVID-19 [36]. However, several 
Table 2 Contentious issues and unanswered questions regarding diabetes and COVID-19.

(1) Are people with well-controlled diabetes at higher risk of getting COVID-19 infection than non-diabetic individuals?

(2) Is there any effect of obesity on the severity of COVID-19 in people with diabetes?

(3) Is there any specific diet or supplement which could help patients of diabetes and COVID-19?

(4) What is the role of renin angiotensin aldosterone system (RAAS) and inhibitors of RAAS in determining the predisposition to COVID-19 and its severity?

(5) Do different anti-hyperglycaemic drugs have different effects on the disease course in COVID-19?

(6) Is the viral clearance slower in patients with diabetes (which could mean higher infectivity)?

(7) Can COVID-19 lead to beta-cell dysfunction/destruction?

(8) Is there an effect of COVID-19 directly on diabetes-related complications independent of glycaemic deterioration?

(9) What are the effects of 'lockdown' on glycaemia and diabetesrelated complications?

(10) Does reduction in air pollution because of restrictions on vehicular movement and industries have a beneficial role in control of blood glucose?

(11) Can telemedicine help in management of diabetes in the times of COVID-19?

(12) Is it useful and/or feasible to screen all people with diabetes for SARS CoV-2?

(13) Are there any ethnicity-specific factors determining the different risk of infection, disease severity and mortality rates in different regions?

unanswered questions remain, about which the knowledge and information is limited. Clearly, further research could lead to important insights (Table 2). Some of these are discussed below.

(1) What is the natural history of COVID-19 in patients with diabetes? The natural course of the disease after infection of patients with diabetes with SARS CoV-2 has not been documented well. For example, we don't know if the incubation period is different in people with diabetes. It is also possible those patients of diabetes who are young, have short duration of diabetes, and well controlled may have less severe COVID-19 infection. There is a possibility of reduced viral clearance in diabetes as has been reported in patients who are on corticosteroids [37]. This could have public health implications as the patients with diabetes could remain infectious for a longer period than those without diabetes.

(2) Use of drugs in treatment of COVID-19 which could have effect on glycaemia:

a. Chloroquine has also been licensed for use in India for patients with type 2 diabetes. Although the efficacy of chloroquine is not proven; it has been used in patients with COVID-19 [38]. Chloroquine has a weak anti-hyperglycaemic effect and there is a theoretical risk of hypoglycaemia when used in combination with other antihyperglycaemic drugs.

b. Corticosteroids, though neither effective nor recommended, are frequently used in ARDS and sepsis and would worsen glycemic levels.

(3) COVID-19 and pancreatic beta cells: there is significant expression of ACE2 receptors in pancreatic islets and hyperglycaemia lasting up to 3 years has been reported in patients with SARS [39]. Direct injury to beta cells is a possibility and patients recovering from COVID-19 might need major changes in anti-hyperglycaemic regimen. Recently, new-onset diabetes has been reported in patients with COVID-19 [11].

(4) Suboptimal lifestyle measures and other issues during lockdown:

a. There are restrictions on movement of people and 'lockdowns' in several parts of the world in order to contain the pandemic. This poses some challenges in the evaluation and treatment of patients with diabetes. There are limited opportunities for exercise as regular walks and visits to gyms or swimming pools are not possible. Dietary irregularity could occur because of staying at home.

b. There is considerable mental stress because of the unpredictability of the disease as well as social immobility as brought out in an excellent study in healthy people in China at the time when there was a huge burden of COVID-19 there [40].

c. Patients may find it difficult to procure healthy foods, medicines, insulin, needles and glucose strips etc. because of partial or complete lockdowns. The problem becomes more pronounced with elderly, poor and disadvantaged sections of society.

d. There could be underreporting of symptoms because of the perceived need to avoid visiting hospitals.

All these factors could cause glucose dysregulation and could predispose patients to complications like infections, hyperosmolar coma, ketoacidosis and even acute cardiac events. A prediction model of the effect of lockdown in India on blood glucose showed a $3.6 \%$ increase in $\mathrm{HbA} 1 \mathrm{c}$ at the end of 45 days of lockdown and future increase in diabetes-related complications [41]. 
(5) Use of remote education and advice: Telemedicine (also emails, texts) can be very helpful in these times to impart education and has been shown to improve glycaemia. Telemedicine guidelines for physicians in India have been published [42]. Patients need to be educated about the need to visit the hospital urgently in emergency situations like vomiting, drowsiness, shortness of breath, chest pain, weakness of limbs, altered sensorium, etc [43].

(6) COVID-19 testing for all patients with diabetes? Given the increased severity of COVID-19 in patients with diabetes, a case could be made for testing of all people with diabetes for the presence of disease. That would be a humongous task considering the high prevalence of diabetes. High-risk groups like those with high HbAlc, those with comorbidities, long duration of diabetes or elderly could be chosen for testing, however, utility of this approach remains to be proven, There are frequent false negative tests and repeated testing may be required in asymptomatic individuals. Since there is no treatment currently recommended for asymptomatic people, therefore apart from isolating them, detecting these patients might not prove meaningful clinically.

(7) Ethnic variations in severity of COVI19 in patients with diabetes? In the United States, the disease has caused disproportionately more fatalities in Blacks and Asians compared with Whites [44]. South Asia, Africa and Korea have seen much lower mortality than rest of the world. Whether it is because of the different approaches topublic health measures, innate immunity or due to some ethnicity-specific variability in response to viral infection, or availability of good medical resources, remains to be studied. Interactions between ethnicity, diabetes and severity of COVID-19 will be of interest, considering the racial disparities in the prevalence of diabetes. According to a recent report, prevalence of COVID-19 and mortality due to the disease correlated significantly with frequency of $\mathrm{D}$ allele in ACE gene [45]. Such polymorphisms in ACE gene as well as several other genes involved in the pathophysiology of COVID-19 might be responsible for individual and ethnic variations in disease course.

(8) Benefits of lockdown? There could be some positive effects of the social restrictions.

a. Patients have more time for self-care and could pay more attention to diet and exercise if motivated.

b. Some people have stopped or reduced alcohol and smoking because of non-availability.

c. There has been significant fall in air pollution as a result of reduced industrial and vehicular emissions [46]. Increase in blood glucose has been reported with short-term rise in $\mathrm{pm}^{10}$ (particulate matter $<10$ microns in diameter) and glycaemic improvement could occur with the fall in pollution [47].

In view of the issues highlighted above, it is important to recognise the importance of diabetes as a vital comorbidity in patients with COVID-19. There are several contentious issues and the ongoing research will hopefully shed more light on the behaviour of COVID-19 in patients with diabetes.

Author contributions RG and AM planned the outline of manuscript. $\mathrm{RG}$ reviewed the literature and wrote the manuscript. RG, AM and $\mathrm{AH}$ edited the manuscript.

\section{Compliance with ethical standards}

Conflict of interest The authors declare that they have no conflict of interest.

Publisher's note Springer Nature remains neutral with regard to jurisdictional claims in published maps and institutional affiliations.

\section{References}

1. Yang J, Zheng Y, Gou X, Pu K, Chen Z, Guo Q, et al. Prevalence ofcomorbidities in the novel Wuhan coronavirus (COVID-19) infection: asystematicreview and meta-analysis. Int $\mathrm{J}$ Infect Dis. 2020. pii: S1201-9712(20)30136-3. https://doi.org/10.1016/j.ijid. 2020.03.017.

2. Wu C, Chen X, Cai Y, Xia J, Zhou X, Xu S, et al. Risk factors associated with acute respiratory distress syndrome and death in patients with coronavirus disease 2019 pneumonia in Wuhan, China. JAMA Intern Med. 2020. https://doi.org/10.1001/jama internmed.2020.0994.

3. Chen Y, Gong X, Guo J. Effects of hypertension, diabetes and coronary heart disease on COVID-19 diseases severity: a systematic review and meta-analysis. 2020. https://www.medrxiv. org/content/10.1101/2020.03.25.20043133v1.

4. Wu Z, McGoogan JM. Characteristics of and important lessons from the coronavirus disease 2019 (COVID-19) outbreak in China: summary of a report of 72314 cases from the Chinese Center for Disease Control and Prevention. JAMA. 2020. https:// doi.org/10.1001/jama.2020.2648.

5. Bode B, Garrett V, Messler J, McFarland R, Crowe J, Booth R, et al. Glycemic characteristics and clinical outcomes of COVID19 patients hospitalized in the United States. J Diabetes Sci Technol. 2020. https://doi.org/10.1177/1932296820924469.

6. Carey IM, Critchley JA, DeWilde S, Harris T, Hosking FJ, Cook DG. Glycemic control and risk of infections among people with type 1 or type 2 diabetes in a large primary care cohort study. Diabetes Care 2018;41:513-21. https://doi.org/10.2337/dc172131.

7. Ferlita S, Yegiazaryan A, Noori N, Lal G, Nguyen T, To K, et al. Type 2 diabetes mellitus and altered immune system leading to 
susceptibility to pathogens, especially mycobacterium tuberculosis. J Clin Med. 2019;8:2219. https://doi.org/10.3390/ jem8122219.

8. Nyambuya TM, Dludla PV, Mxinwa V, Nkambule BB. T-cell activation and cardiovascular risk in adults with type 2 diabetes mellitus: A systematic review and meta-analysis. Clin Immunol. 2020;210:108313. https://doi.org/10.1016/j.clim.2019.108313.

9. Maddaloni E, Buzzetti R. Covid-19 and diabetes mellitus: unveiling the interaction of two pandemics. Diabetes Metab Res Rev. 2020:e33213321. https://doi.org/10.1002/dmrr.3321.

10. Huttunen R, Syrjänen J. Obesity and the risk and outcome of infection. Int J Obes. 2013;37:333-40.

11. Ji HL, Zhao R, Matalon S, Matthay MA. Elevated Plasmin(ogen) as a common risk factor for COVID-19 susceptibility. Physiol Rev. 2020;100:1065-75. https://doi.org/10.1152/physrev.00013. 2020.

12. Guo W, Li M, Dong Y, Zhou H, Zhang Z, Tian C, et al. Diabetes is a risk factor for the progression and prognosis of COVID-19. Diabetes Metab Res Rev. 2020:e3319. https://doi.org/10.1002/ dmrr.3319.

13. Fernandez C, Rysa J, Almgren P, Nilsson J, Engström G, OrhoMelander M, et al. Plasma levels of the proprotein convertase furinandincidence of diabetes and mortality. J Intern Med. 2018;284:377-87. https://doi.org/10.1111/joim.12783.

14. Hoffmann M, Kleine-Weber H, Krüger N, Müller M, Drosten C, Pöhlmann S. The novel coronavirus 2019 (2019-nCoV) uses the SARS-coronavirus receptor ACE2 and the cellular protease TMPRSS2 for entry into target cells. 2020. https://doi.org/10. 1101/2020.01.31.929042.

15. Li XC, Zhang J, Zhuo JL. The vasoprotective axes of the reninangiotensin system:physiological relevance and therapeutic implications in cardiovascular, hypertensive and kidney diseases. Pharm Res. 2017;125:21-38.

16. Mendy A, Gopal R, Alcorn JF, Forno E. Reduced mortality from lower respiratory tract disease in adult diabetic patients treated with metformin. Respirology. 2019;24:646-51.

17. Zhang W, Xu YZ, Liu B, Wu R, Yang YY, Xiao XQ, et al. Pioglitazone upregulates angiotensin converting enzyme 2 expression in insulin-sensitive tissues in rats with high-fat dietinduced nonalcoholic steatohepatitis. Sci World J. 2014:603409. https://doi.org/10.1155/2014/603409.

18. Romaní-Pérez M, Outeiriño-Iglesias V, Moya CM, Santisteban P, González-Matías LC, Vigo E, et al. Activation of the GLP-1 receptor by liraglutide increases ACE2 expression, reversing right ventricle hypertrophy, and improving the production of SP-A and SP-B in the lungs of type 1 diabetes rats. Endocrinology. 2015;156:3559-69.

19. Arabi YM, Balkhy HH, Hayden FG, Bouchama A, Luke T, Baillie $\mathrm{JK}$, et al. Middle east respiratory syndrome. N Engl J Med. 2017;376:584-94. https://doi.org/10.1056/NEJMsr1408795.

20. Yang W, Cai X, Han X, Ji L. DPP-4 inhibitors and risk of infections: a meta-analysis of randomized controlled trials. Diabetes Metab Res Rev. 2016;32:391-404. https://doi.org/10.1002/ dmrr.2723.

21. Filippatos TD, Liontos A, Papakitsou I, Elisaf MS. SGLT2 inhibitors cardioprotection: a matter debate and multiple hypotheses. Postgrad Med. 2019;131:82-88. https://doi.org/10.1080/ 00325481.2019 .1581971$.

22. Couselo-Seijas M, Agra-Bermejo RM, Fernández AL, MartínezCereijo JM, Sierra J, Soto-Pérez M. High released lactate by epicardial fat from coronary artery disease patients is reduced by dapagliflozin treatment. Atherosclerosis. 2020;292:60-69. https:// doi.org/10.1016/j.atherosclerosis.2019.11.016.

23. Salem ESB, Grobe N, Elased KM. Insulin treatment attenuates renal ADAM17 and ACE2 shedding in diabetic Akita mice. Am J Physiol-Ren Physiol. 2014;306:F629-39.
24. Cure E, Cumhur Cure M. Comment on "organ-protective effect of angiotensin-converting Enzyme 2 and its effect on the prognosis of COVID-19”. J Med Virol. 2020. https://doi.org/10.1002/jmv. 25848.

25. Bilodeau MS, Leiter JC. Angiotensin 1-7 in the rostroventrolateral medulla increases blood pressure and splanchnic sympathetic nerve activity in anesthetized rats. RespirPhysiolNeurobiol. 2018;247:103-11.

26. Yang P, Gu H, Zhao Z, Wang W, Cao B, Lai C, et al. Angiotensin converting enzyme 2 (ACE2) mediates influenza H7N9 virusinduced acute lunginjury. Sci Rep. 2014;4:7027.

27. Fedson DS, Jacobson JR, Rordam OM, Opal SM. Treating the host response to Ebola virus disease with generic statins and angiotensin receptor blockers. mBio. 2015;6:e00716. https://doi. org/10.1128/mBio.00716-15.

28. Khan A, Benthin C, Zeno B, Albertson TJ, Boyd J, Christie JD, et al. A pilot clinical trial of recombinant human angiotensin converting enzyme 2 in acute respiratory distress syndrome. Crit Care. 2017;21:234.

29. Peng YD, Meng K, Guan HQ, Leng L, Zhu RR, Wang BY, et al. Clinical characteristics and outcomes of 112 cardiovascular disease patients infected by 2019-nCoV. Zhonghua Xin Xue Guan Bing Za Zhi. 2020;48:E004. https://doi.org/10.3760/cma.j. cn112148-20200220-00105.

30. Guo T, Fan Y, Chen M, Wu X, Zhang L, He T, et al. Cardiovascular Implications of fatal outcomes of patients with coronavirus disease 2019 (COVID-19). JAMA Cardiol. 2020;27: e201017. https://doi.org/10.1001/jamacardio.2020.1017.

31. Richardson S, Hirsch JS, Narasimhan M, Crawford JM, McGinn $\mathrm{T}$, Davidson KW, et al. Presenting characteristics, comorbidities, and outcomes among 5700 patients hospitalized with COVID-19 in the New York City area. JAMA. 2020. https://doi.org/10.1001/ jama.2020.6775.

32. Zhang, Zhu L, Cai L, Lei F, et al. Association of inpatient use of angiotensin converting enzyme inhibitors and angiotensinii receptor blockers with mortality among patients with hypertension hospitalized with COVID-19. Circ Res. 2020. https://doi.org/10. 1161/CIRCRESAHA.120.317134.

33. Chen D, Li X, Song Q, Hu C, Su F, Dai J, et al. Hypokalemia and clinical implications in patients with coronavirus disease 2019 (COVID-19). 2020. https://doi.org/10.1101/2020.02.27. 20028530.

34. Zhang, Zhu L, Cai L, Lei F, Qin JJ, Xie J, et al. Association of inpatient use of angiotensin converting enzyme inhibitors and angiotensinii receptor blockers with mortality among patients with hypertension hospitalized with COVID-19. Circ Res. 2020. https://doi.org/10.1161/CIRCRESAHA.120.317134.

35. Gupta R, Misra A. Contentious issues and evolving concepts in the clinical presentation and management of patients with COVID-19 infection with reference to use of therapeutic and other drugs used in Co-morbid diseases (Hypertension, diabetes etc). Diabetes Metab Syndr. 2020;14:251-4. https://doi.org/10.1016/j. dsx.2020.03.012.

36. Hussain A, Bhowmik B, do Vale Moreira NC. COVID-19 and diabetes: knowledge in progress. Diabetes Res Clin Pract. 2020:108142. https://doi.org/10.1016/j.diabres.2020.108142.

37. Han Y, Jiang M, Xia D, He L, Lv X, Liao X, et al. COVID-19 in a patient with long-term use of glucocorticoids: A study of a familial cluster. Clin Immunol. 2020;214:108413. https://doi.org/ 10.1016/j.clim.2020.108413.

38. Singh AK, Singh A, Shaikh A, Singh R, Misra A. Chloroquine and hydroxychloroquine in the treatment of COVID-19 with or without diabetes: a systematic search and a narrative review with a special reference to India and other developing countries. Diabetes Metab Syndr. 2020;14:241-6. https://doi.org/10.1016/j.dsx.2020. 03.011. 
39. Yang JK, Lin SS, Ji XJ, Guo LM. Binding of SARS coronavirus to its receptor damages islets and causes acute diabetes. Acta Diabetol. 2010;47:193-9. https://doi.org/10.1007/s00592-009-0109-4.

40. Zhang SX, Wang Y, Rauch A, Wei F. Unprecedented disruption of lives and work: health, distress and life satisfaction of working adults in China one monthinto the COVID-19 outbreak. Psychiatry Res. 2020;288:112958. https://doi.org/10.1016/j.psychres. 2020.112958.

41. Ghosal S, Sinha B, Majumder M, Misra A. Estimation of effects of nationwide lockdown for containing coronavirus infection on worsening of glycosylated haemoglobin and increase in diabetesrelated complications: a simulation model using multivariate regression analysis. Diabetes Metab Syndr. 2020;14:319-23. https://doi.org/10.1016/j.dsx.2020.03.014.

42. Ghosh A, Gupta R, Misra A. Telemedicine for diabetes care in India during COVID19 pandemic and national lockdown period: guidelines for physicians. Diabetes Metab Syndr. 2020;14:273-6. https://doi.org/10.1016/j.dsx.2020.04.001.
43. Gupta R, Ghosh A, Singh AK, Misra A. Clinical considerations for patients with diabetes in times of COVID-19 epidemic. Diabetes Metab Syndr. 2020;14:211-2. https://doi.org/10.1016/j.dsx. 2020.03.002.

44. APM Research Lab. The color of coronavirus, COVID-19 deaths by race and ethnicity in the U.S. APM Research Lab; 2020. https://www.apmresearchlab.org/covid/deaths-by-race.

45. Delanghe JR, Speeckaert MM, De Buyzere ML. The host's angiotensin-converting enzyme polymorphism may explain epidemiological findings in COVID-19 infections. Clin Chim Acta. 2020;505:192-3. https://doi.org/10.1016/j.cca.2020.03.031.

46. Dutheil F, Baker JS, Navel V. COVID-19 as a factor influencing air pollution? Environ Pollut. 2020;263:114466. https://doi.org/ 10.1016/j.envpol.2020.114466.

47. Yang BY, Fan S, Thiering E, Seissler J, Nowak D, Dong GH. et al. Ambientair pollution and diabetes: a systematic review and meta-analysis. Environ Res. 2020;180:108817. https://doi.org/10. 1016/j.envres.2019.108817. 